\title{
A study of fluctuating asymmetry in hybrids of dwarf and normal lake whitefish ecotypes (Coregonus clupeaformis) from different glacial races
}

\author{
GUOQING LU \& LOUIS BERNATCHEZ* \\ GIROQ, Département de biologie, Université Laval, Sainte-Foy, Québec, Canada G1K 7P4
}

\begin{abstract}
Fish ecotypes found in north temperate lakes are increasingly used as model organisms to explore patterns and processes of population divergence that may ultimately cause speciation. Processes involved in their reproductive isolation are, however, still poorly understood. Recent experimental studies on whitefish ecotypes from different glacial races revealed that embryonic mortality of hybrids was 2.4-4.7 times higher than for parental forms. In this study, we compared fluctuating asymmetry (FA) in morphological traits of these same hybrid and pure crosses to test the hypothesis that genetic stress observed in hybrids at embryonic stages is also manifested at later developmental stages. Twelve morphological traits were used to measure asymmetry. Variable degrees of asymmetry were observed depending on traits and crosses, however there was no significant difference in FA among crosses. These results thus provided no evidence in support of the working hypothesis and indicated that genetic stress may differ among life stages. It is more likely that high hybrid embryonic mortality acts together with ecological factors at later stages to increase further the extent of reproductive isolation between sympatric whitefish ecotypes.
\end{abstract}

Keywords: fluctuating asymmetry, hybrids, reproductive isolation, speciation, sympatric ecotypes.

\section{Introduction}

Fish ecotypes found in north temperate lakes are increasingly used as model organisms to study patterns and processes of population divergence that may ultimately lead to speciation events (reviewed in Robinson \& Wilson, 1994; Skúlason \& Smith, 1995; Schluter, 1996). There is now a general consensus that phenotypic divergence observed among sympatric forms evolved as a consequence of divergent selection promoting differential trophic use (Schluter, 1998). In contrast, much less effort has been devoted to the understanding of processes driving reproductive isolation. Previous studies on threespine stickleback (Gasterosteus sp.) and sockeye/kokanee ecotypes (Oncorhynchus nerka) provided no evidence for postmating isolating mechanisms in the form of genetic incompatibility (McPhail, 1984, 1993; Wood \& Foote, 1990, 1996; Hatfield, 1995). This, coupled with exper-

*Correspondence. E-mail: louis.bernatchez@bio.ulaval.ca imental evidence in stickleback for reduced foraging efficiency in hybrids compared to parental forms (Schluter, 1995), suggested that postmating isolation in sympatric fish ecotypes may instead be driven by ecological processes.

Recent studies of lake whitefish (Coregonus clupeaformis) ecotypes, however, have indicated that both ecological and genetic factors might be involved in the development of reproductive isolation. Lakes of the St John River system (south-east Quebec, Canada; northern Maine, USA) harbour sympatric dwarf and normal ecotypes resulting from a postglacial secondary contact between two evolutionary lineages that evolved in allopatry during the Pleistocene (Bernatchez \& Dodson, 1990; Pigeon et al., 1997; Bernatchez et al., 1999). A recent comparative study revealed that gene flow between ecotypes within a lake was negatively correlated with their morphological differentiation based on trophic-related traits, supporting the role of ecological processes in driving reproductive isolation (Bernatchez et al., 1999; Lu \& Bernatchez, 1999). Contrary to previous studies, however, Lu \& Bernatchez (1998) 
experimentally showed that embryonic mortality of hybrids between the two evolutionary lineages was 2.4-4.7 times higher than for parental forms. This provided evidence for a genetic mechanism of postmating isolation.

In this study, we compared fluctuating asymmetry (FA) in morphological traits of the same hybrid and pure progeny studied by Lu \& Bernatchez (1998) to test the hypothesis that genetic stress observed in hybrids at embryonic stages is also manifested at later developmental stages. Fluctuating asymmetry has been widely used as a measure of developmental stability (Van Valen, 1962), defined as the ability of an organism to buffer its developmental processes against genetic and/ or environmental disturbances (Waddington, 1942). Although the genetic bases of developmental stability are still under discussion (Clarke, 1993), two major factors, genomic coadaptation and heterozygosity, are commonly invoked to explain the stability of developmental processes (Leary \& Allendorf, 1989). Consequently, the extent of developmental stability manifested in hybrid individuals results from a balance between the stabilizing effect of increased heterozygosity and the disruptive effect of genomic coadaptation. Given the high embryonic mortality rate previously observed in hybrids, we predicted that FA should be higher in hybrid than in pure progeny of the two whitefish evolutionary lineages used in this study.

\section{Materials and methods}

\section{Origin of fish and rearing conditions}

Adult fish for the two whitefish evolutionary lineages were obtained from Témiscouta Lake (dwarf ecotype D, Acadian race) and Aylmer Lake (normal ecotype N, Atlantic/Mississipian race). Glacial races refer to the nomenclature used by Bernatchez \& Dodson (1991). The rationale for this sampling scheme was to consider genetic divergence of races before they came into contact. These fish were used to produce two pure $\left(D_{F} D_{M}\right.$ and $\left.N_{F} N_{M}\right)$ and two reciprocal hybrid crosses $\left(\mathrm{D}_{\mathrm{F}} \mathrm{N}_{\mathrm{M}}\right.$ and $\left.\mathrm{N}_{\mathrm{F}} \mathrm{D}_{\mathrm{M}}\right)$, as detailed in $\mathrm{Lu}$ \& Bernatchez (1998).

Rearing conditions and daily routine were the same among crosses during all rearing phases ( $\mathrm{Lu} \&$ Bernatchez, 1998). Larvae were fed with live Artemia nauplii and formatted diet (Fry Feed Kyowa Inc.), whereas fish were fed with pellet food (More-Clark Inc.) following metamorphosis. Progeny of each cross were raised in separate $1000-\mathrm{L}$ tanks and subsequently transferred into 3000-L tanks at one year of age. All fish were 20 months of age when measurements were taken.

\section{Fluctuating asymmetry}

On average, 26 fish were analysed for each group. Morphological asymmetry was estimated for six morphological traits and six meristic traits (Table 1). Morphological traits were measured to the nearest $0.1 \mathrm{~mm}$ using an electronic calliper. Gill rakers were counted on the first gill arch under a dissecting microscope. More details on these traits and methodology are presented in Chouinard et al. (1996) and Hatfield (1997).

Because measurement error may potentially either hide or bias real differences between sides (Palmer, 1994), we independently repeated the measurements for all traits in all samples. Repeatability was assessed as Pearson correlation coefficients between the two sets of measurements (Hatfield, 1997).

Asymmetry was calculated as the value of left side minus right side measurement $(\mathrm{R}-\mathrm{L})$, whereas FA corresponded to their absolute values $(|\mathrm{R}-\mathrm{L}|)$. We also quantified another FA index, $\sigma^{2}$, i.e. FA10 of Palmer (1994), from a two-way (sides $\times$ individuals) ANOVA as it allows measurement error variance to be partitioned out of the total between-sides variance, lending itself to be the most powerful index in testing for differences between samples (Palmer, 1994). This index includes both contributions from antisymmetry and FA. None of $48 \mathrm{R}-\mathrm{L}$ distributions showed a platykurtic (broadpeaked or bimodal) departure from normality (Lilliefors $P>0.05$ ), and thus no antisymmetry was present. Consequently, the $\sigma^{2}$-value reflects the magnitude of FA in our study (Palmer \& Strobeck, 1986). Significance of $\sigma^{2}$ was tested again using the sides $\times$ individuals ANOvA (Palmer, 1994).

In order to test whether FA correlated with trait size within samples, we performed regressions of FA against total body length. Significant regressions were observed for two traits (see Results) and in these cases size corrections were applied using the allometry method as detailed in Reist (1985).

We used a one-sample $t$-test to examine whether mean asymmetry (MA) of each trait deviated from zero. Significant departures from 0 , indicating directional asymmetry (DA), were observed for three traits. These were therefore excluded from further analyses (Table 2) (Palmer, 1994).

Levene's ANOva test was used to assess differences of FA in individual traits among crosses. This method is particularly sensitive to small differences in FA among samples, and least sensitive to departures from normality in the direction of leptokurtosis or platykurtosis. It is thus more likely to detect as significant small differences in FA and be robust (i.e. $P$-values valid) to nonnormality (Palmer, 1994; Hatfield, 1997). To corroborate the results of Levene's test, we also performed the 
Table 1 Description of morphological asymmetry in lake whitefish crosses. $R$, repeatability (Pearson correlation coefficients between two data sets of measurements); $r$, regression coefficients of fluctuating asymmetry (FA) against body length; SE, standard error; $\sigma^{2}$, the magnitude of nondirectional asymmetry, herein reflecting FA. Asterisks indicate significant regression $(r)$, mean asymmetry (MA) and fluctuating asymmetry $\left(\sigma^{2}\right)$, following sequential Bonferroni corrections $(\alpha=0.05, k=48)$

\begin{tabular}{|c|c|c|c|c|c|c|c|}
\hline Crosses & Variables & $N$ & $R$ & $r$ & MA (SE) & FA (SE) & $\sigma^{2}$ \\
\hline \multirow{12}{*}{$\mathrm{D}_{\mathrm{F}} \mathrm{D}_{\mathrm{M}}$} & Gill raker counts & 33 & 1.000 & 0.021 & $-0.235(0.378)$ & $0.853(0.350)$ & $0.263 *$ \\
\hline & Head length & 33 & 0.628 & 0.108 & $0.248(0.184)$ & $0.680(0.126)$ & $0.288 *$ \\
\hline & Interorbital width & 33 & 0.743 & 0.072 & $0.082(0.070)$ & $0.327(0.043)$ & 0.020 \\
\hline & Longest gill raker length & 33 & 0.685 & 0.005 & $-0.020(0.044)$ & $0.168(0.026)$ & $0.017 *$ \\
\hline & Lateral line scale & 33 & 0.785 & 0.238 & $0.500(0.340)$ & $1.676(0.194)$ & $2.047 *$ \\
\hline & Maxillary length & 33 & 0.884 & 0.226 & $-0.041(0.116)$ & $0.472(0.082)$ & $0.183^{*}$ \\
\hline & Maxillary width & 33 & 0.669 & 0.040 & $-0.012(0.023)$ & $0.116(0.012)$ & 0.004 \\
\hline & Pectoral fin ray counts & 33 & 1.000 & 0.193 & $0.206(0.082)$ & $0.206(0.082)$ & $0.115^{*}$ \\
\hline & Pelvic fin ray counts & 33 & 1.000 & 0.060 & $0.029(0.089)$ & $0.206(0.082)$ & $0.136^{*}$ \\
\hline & Postorbital length & 33 & 0.732 & $0.467 *$ & $0.377(0.119)^{*}$ & $0.599(0.072)$ & 0.104 \\
\hline & Scales above the lateral line & 33 & 1.000 & 0.020 & $0.015(0.045)$ & $0.074(0.043)$ & $0.030^{*}$ \\
\hline & Suprapelvic scale & 33 & 1.000 & 0.131 & $0.029(0.029)$ & $0.029(0.029)$ & $0.015^{*}$ \\
\hline \multirow[t]{12}{*}{$\mathrm{N}_{\mathrm{F}} \mathrm{N}_{\mathrm{M}}$} & Gill raker counts & 31 & 1.000 & 0.115 & $-0.032(0.135)$ & $0.419(0.111)$ & $0.283^{*}$ \\
\hline & Head length & 31 & 0.661 & 0.220 & $0.036(0.211)$ & $0.899(0.133)$ & $0.421 *$ \\
\hline & Interorbital width & 31 & 0.823 & 0.061 & $-0.112(0.115)$ & $0.497(0.074)$ & $0.158^{*}$ \\
\hline & Longest gill raker length & 31 & 0.774 & $0.457^{*}$ & $0.013(0.031)$ & $0.124(0.021)$ & $0.013^{*}$ \\
\hline & Lateral line scale & 31 & 0.994 & 0.231 & $0.387(0.412)$ & $1.903(0.232)$ & $2.681^{*}$ \\
\hline & Maxillary length & 31 & 0.717 & 0.194 & $-0.593(0.076)^{*}$ & $0.630(0.065)$ & $0.073^{*}$ \\
\hline & Maxillary width & 31 & 0.814 & 0.307 & $-0.012(0.037)$ & $0.166(0.021)$ & $0.018 *$ \\
\hline & Pectoral fin ray counts & 31 & 1.000 & 0.103 & $0.032(0.073)$ & $0.161(0.067)$ & $0.075^{*}$ \\
\hline & Pelvic fin ray counts & 31 & 1.000 & 0.077 & $-0.161(0.082)$ & $0.226(0.076)$ & $0.103 *$ \\
\hline & Postorbital length & 31 & 0.725 & 0.088 & $0.213(0.163)$ & $0.757(0.095)$ & $0.342 *$ \\
\hline & Scales above the lateral line & 31 & 1.000 & 0.000 & $0.000(0.000)$ & $0.000(0.000)$ & 0.000 \\
\hline & Suprapelvic scale & 31 & 1.000 & 0.000 & $0.000(0.000)$ & $0.000(0.000)$ & 0.000 \\
\hline \multirow[t]{12}{*}{$\mathrm{N}_{\mathrm{F}} \mathrm{D}_{\mathrm{M}}$} & Gill raker counts & 20 & 1.000 & 0.275 & $0.050(0.211)$ & $0.650(0.150)$ & $0.446^{*}$ \\
\hline & Head length & 20 & 0.670 & 0.002 & $0.012(0.203)$ & $0.882(0.116)$ & $0.485^{*}$ \\
\hline & Interorbital width & 20 & 0.812 & 0.038 & $-0.025(0.100)$ & $0.368(0.054)$ & $0.082 *$ \\
\hline & Longest gill raker length & 20 & 0.761 & 0.245 & $0.009(0.044)$ & $0.159(0.025)$ & $0.018 *$ \\
\hline & Lateral line scale & 20 & 1.000 & 0.039 & $0.125(0.535)$ & $1.675(0.374)$ & $2.861 *$ \\
\hline & Maxillary length & 20 & 0.857 & 0.019 & $-0.673(0.171)^{*}$ & $0.862(0.117)$ & $0.269 *$ \\
\hline & Maxillary width & 20 & 0.708 & 0.120 & $-0.045(0.043)$ & $0.125(0.034)$ & $0.015^{*}$ \\
\hline & Pectoral fin ray counts & 20 & 1.000 & 0.099 & $0.100(0.100)$ & $0.200(0.092)$ & $0.100^{*}$ \\
\hline & Pelvic fin ray counts & 20 & 1.000 & 0.291 & $0.200(0.138)$ & $0.400(0.112)$ & $0.189 *$ \\
\hline & Postorbital length & 20 & 0.812 & 0.347 & $0.281(0.175)$ & $0.745(0.117)$ & $0.232 *$ \\
\hline & Scales above the lateral line & 20 & 1.000 & 0.000 & $0.050(0.050)$ & $0.050(0.050)$ & $0.025^{*}$ \\
\hline & Suprapelvic scale & 20 & 1.000 & 0.000 & $0.050(0.050)$ & $0.050(0.050)$ & $0.025^{*}$ \\
\hline \multirow[t]{12}{*}{$\mathrm{D}_{\mathrm{F}} \mathrm{N}_{\mathrm{M}}$} & Gill raker counts & 20 & 1.000 & 0.110 & $0.050(0.185)$ & $0.650(0.109)$ & $0.341 *$ \\
\hline & Head length & 20 & 0.742 & 0.386 & $-0.084(0.132)$ & $0.459(0.082)$ & 0.093 \\
\hline & Interorbital width & 20 & 0.677 & 0.039 & $0.339(0.101)^{*}$ & $0.463(0.071)$ & $0.092 *$ \\
\hline & Longest gill raker length & 20 & 0.891 & 0.120 & $0.076(0.034)$ & $0.134(0.022)$ & $0.010^{*}$ \\
\hline & Lateral line scale & 20 & 0.996 & 0.182 & $0.050(0.505)$ & $1.950(0.235)$ & $2.514^{*}$ \\
\hline & Maxillary length & 20 & 0.905 & 0.035 & $-0.606(0.110)^{*}$ & $0.684(0.082)$ & 0.076 \\
\hline & Maxillary width & 20 & 0.818 & 0.237 & $-0.014(0.040)$ & $0.150(0.021)$ & $0.012 *$ \\
\hline & Pectoral fin ray counts & 20 & 1.000 & 0.096 & $-0.050(0.114)$ & $0.250(0.099)$ & $0.124 *$ \\
\hline & Pelvic fin ray counts & 20 & 1.000 & 0.290 & $-0.050(0.114)$ & $0.250(0.099)$ & $0.124^{*}$ \\
\hline & Postorbital length & 20 & 0.664 & 0.208 & $0.413(0.188)$ & $0.773(0.114)$ & $0.270^{*}$ \\
\hline & Scales above the lateral line & 20 & 1.000 & 0.157 & $0.000(0.000)$ & $0.000(0.000)$ & 0.000 \\
\hline & Suprapelvic scale & 20 & 1.000 & 0.182 & $0.000(0.000)$ & $0.000(0.000)$ & 0.000 \\
\hline
\end{tabular}

(c) The Genetical Society of Great Britain, Heredity, 83, 742-747. 
Table 2 Tests for differences in fluctuating asymmetry (FA) indices of morphological traits among crosses. Traits with directional asymmetry (postorbital length, maxillary length and interorbital width) and no significant FA (scale counts above the lateral line and suprapelvic scale counts) were excluded from the tests

\begin{tabular}{|c|c|c|c|c|c|c|c|c|}
\hline \multirow[b]{3}{*}{ Traits } & \multicolumn{4}{|c|}{ ANOVA on FA } & \multirow{2}{*}{\multicolumn{2}{|c|}{$\begin{array}{l}\text { Multivariate } \\
\text { ANOVA on FA }\end{array}$}} & \multirow{2}{*}{\multicolumn{2}{|c|}{$\begin{array}{l}\text { Kruskal-Wallis } \\
\text { ANOvA on } \sigma^{2}\end{array}$}} \\
\hline & \multicolumn{2}{|c|}{ Levene’s } & \multicolumn{2}{|c|}{ Kruskal-Wallis } & & & & \\
\hline & $F_{3,100}$ & $P$ & $\chi^{2}$ & $P$ & Wilks's Lambda & $P$ & $\chi^{2}$ & $P$ \\
\hline Gill raker counts & 0.976 & 0.408 & 4.649 & 0.199 & & & & \\
\hline Head length & 3.050 & 0.033 & 4.250 & 0.236 & & & & \\
\hline $\begin{array}{l}\text { Longest gill raker } \\
\text { length }\end{array}$ & 1.012 & 0.391 & 2.528 & 0.470 & & & & \\
\hline Lateral line scale & 0.862 & 0.464 & 0.047 & 0.997 & & & & \\
\hline Maxillary width & 0.904 & 0.443 & 5.025 & 0.170 & & & & \\
\hline Pectoral fin ray counts & 0.948 & 0.421 & 0.686 & 0.877 & & & & \\
\hline Pelvic fin ray counts & 4.136 & 0.009 & 3.496 & 0.321 & & & & \\
\hline Total & & & & & 0.816 & 0.693 & 1.579 & 0.664 \\
\hline
\end{tabular}

nonparametric Kruskal-Wallis ANOva to test for differences in FA in individual traits.

Because variation in FA is often subtle, FA of individual traits may not differ substantially among samples. Consequently, we conducted multivariate ANOVAs (samples $\times$ traits) as recommended by Palmer (1994). A significant $P$-value among samples implied that multiple traits exhibited consistently higher FA in some samples than others. The Kruskal-Wallis ANOVA was also used to test for global differences in $\sigma^{2}$ of morphological traits among crosses.

The $\alpha$-level of related tests was adjusted following the sequential Bonferroni correction to minimize type I errors (Rice, 1989). All statistical analyses were performed using STATISTICA, version 4.5 (Statsoft).

\section{Results}

\section{Measurement error, size correction and DA}

Measurement errors were low. The two data sets of measurements for all traits were highly correlated $(P<0.0001)$, with repeatability being, on average, 0.874 (Table 1). Correlation between FA and body length was observed in two out of 48 cases, postorbital length in $\mathrm{D}_{\mathrm{F}} \mathrm{D}_{\mathrm{M}}$ and longest gill raker length in $\mathrm{N}_{\mathrm{F}} \mathrm{N}_{\mathrm{M}}$ (Table 1). This correlation was as expected by chance alone $(\alpha<0.05)$. Fluctuating asymmetry values of the above traits were size-adjusted for cross comparisons (Reist, 1985). One-sample $t$-tests of the null hypothesis that $\mathrm{MA}=0$ revealed $\mathrm{DA}$ in postorbital length of $D_{F} D_{M}$, maxillary length of $N_{F} N_{M}$, $N_{F} D_{M}$ and $D_{F} N_{M}$, and interorbital width of $D_{F} N_{M}$. These traits were thus excluded from further analyses (Table 2).

\section{Fluctuating asymmetry}

Variable levels of asymmetry were observed depending on traits (Table 1). No FA was observed for scale counts above the lateral line and suprapelvic scale counts in $\mathrm{N}_{\mathrm{F}} \mathrm{N}_{\mathrm{M}}$ and $\mathrm{D}_{\mathrm{F}} \mathrm{N}_{\mathrm{M}}$, whereas $\mathrm{FA}$ was maximal in lateral line scale counts in all crosses. Significant FA was observed for eight to 12 traits depending on group after removing the effect of measurement errors (Table 1).

\section{Differences in FA among samples}

Tests of both parametric and nonparametric ANOvAs revealed no difference in average FA of morphological traits among crosses (Table 2). Levene's tests revealed $P$-values smaller than 0.05 in pelvic fin ray counts and head length, but differences in FA among crosses were not significant following sequential Bonferroni corrections, indicating homogeneity of variances in FA among crosses. The Kruskal-Wallis ANOvAs corroborated the Levene's tests in showing no statistical differences in individual traits among crosses.

The absence of differences in morphological FA among crosses was also supported by a multivariate ANOvA on FA and the Kruskal-Wallis ANOvA on $\sigma^{2}$ (Table 2).

\section{Discussion}

Assuming that FA does reflect developmental stability (Van Valen, 1962; Leary et al., 1984), our results do not suggest that hybrids were less fit than parental forms of dwarf and normal whitefish ecotypes from different glacial races. Previous studies of FA in fishes and other

(C) The Genetical Society of Great Britain, Heredity, 83, 742-747. 
organisms revealed either increased, decreased or similar FA in hybrid progeny compared to parental populations (reviewed in Palmer \& Strobeck, 1986; Leary \& Allendorf, 1989). This indicates no consistency in predicting the extent of developmental stability in hybrid organisms. The resulting stability in hybrids of this study probably reflects a balance between the heterozygosity and disruption of genetic coadaptation. Increased heterozygosity in hybrids compared to parental forms may result in higher stability (Leamy, 1984), whereas hybridization results in a breakdown of genomic coadaptation, potentially leading to decreased stability (Graham \& Felley, 1985; Leary et al., 1985). The disruptive effect of genomic coadaptation is generally expected to increase with the extent of genetic divergence between parental taxa or populations (Palmer \& Strobeck, 1986). For instance, the effect of disruption at interspecific or intersubspecific levels is generally greater than that of heterosis (Graham \& Felley, 1985; Leary et al., 1985).

Based on the extent of their divergence, the two races of whitefish analysed here remained in geographical isolation for at least 150000 years and we therefore presumed that a breakdown of genomic coadaptation would be more important than heterosis. This was supported by experiments on the same crosses used in this study which demonstrated that daily embryonic mortality rates were 2.4-4.7 times higher in reciprocal hybrid crosses compared to pure crosses (Lu \& Bernatchez, 1998). These differential levels of mortality between hybrids and pure progeny ranked the highest among values reported at the intraspecific level in fish (McPhail, 1984, 1993; Wood \& Foote, 1990, 1996; Hatfield, 1995). The contrast between the extent of genetic stress observed in whitefish larvae and juvenile fish suggested that the effect of genomic incompatibility might differ among life stages.

Several alternative, but not necessarily exclusive, hypothetical explanations may account for the absence of developmental instability at the juvenile stage, whereas high mortality occurred at embryonic stages. Large numbers of gene systems are presumably involved in development (Zakharov, 1989; Graham, 1992). Different gene systems may be more or less sensitive to disruption of a coadapted genome (Alibert et al., 1994). Although hypothetical, it is possible that embryonic development depends on a limited number of strongly interactive genes which would make this system more sensitive to breakdown than multigenic characters with phenotypes resulting from the additive effect of weakly interactive genes. Given the likely polygenic control of the numerous morphological traits analysed in the study, this would suggest that the number of loci that come under selection in whitefish hybrids might not be very large (Alibert et al., 1994).

It is also possible that the relationship between developmental stability and reproductive fitness, expressed in terms of embryonic survival rate, may be out of phase in hybrids (Graham, 1992). This is because the development of adults is a premeiotic component of reproductive success, whereas survival of offspring is postmeiotic (Graham, 1992).

Finally, it is also possible that the high hybrid mortality rate observed during embryonic development (Lu \& Bernatchez, 1998) resulted in differential survival of progeny, for which the effect of disruptive genetic coadaptation was less important. Selection could have removed the more asymmetrical individuals, and thus may mask the detection of developmental stability as previously suggested in other salmonids (Beacham \& Withler, 1987). Given the approximate selective coefficient(s) of 0.4 against hybrids reported by $\mathrm{Lu}$ \& Bernatchez (1998), this explanation appears rational, although it remains to be empirically supported.

Whatever the cause for the apparent absence of developmental instability in hybrid juvenile fish between the divergent whitefish races found in the secondary contact zone of the St John River drainage, it suggests that postmating isolation related to disrupted genomic coadaptation in hybrids does not act as a reproductive barrier at this life-history stage. Instead, reduced foraging efficiency and/or other ecological attributes may be more important than genetic incompatibility at this later developmental stage, as documented for Gasterosteus ecotypes (Schluter, 1995), and suggested by differential trophic use associated with different phenotypes in pure ecotypes of whitefish (Bernatchez et al., 1999).

\section{Acknowledgements}

We gratefully acknowledge S. Higgins and N. Soucy for laboratory assistance. We also thank T. J. Crawford and two anonymous reviewers for constructive comments on the manuscript. This work was supported by a NSERC (Canada) research grant to L.B. It is a contribution to the programme of GIROQ (Groupe Interuniversitaire de Recherches Océanographiques du Québec).

\section{References}

ALIBERT, P., RENAUD, S., DOD, B., BONHOMME, F. AND AUFFRAY, J. C. 1994. Fluctuating asymmetry in the Mus musculus hybrid zone: a heterotic effect in disrupted co-adapted genomes. Proc. R. Soc. B., 258, 53-59.

BEACHAM, T. D. AND WITHLER, R. E. 1987. Developmental stability and heterozygosity in chum (Oncorhynchus keta) 
and pink (Oncorhynchus gorbuscha) salmon. Can. J. Zool., 65, $1823-1826$.

BERNATCHEZ, L. AND DODSON, J. J. 1990. Allopatric origin of sympatric populations of Lake whitefish (Coregonus clupeaformis) as revealed by mitochondrial-DNA restriction analysis. Evolution, 44, 1263-1271.

Bernatchez, L. AND DODSON, J. J. 1991. Phylogeographic structure in mitochondrial DNA of the Lake whitefish (Coregonus clupeaformis) and its relation to Pleistocene glaciations. Evolution, 45, 1016-1035.

BERNATCHEZ, L., CHOUINARD, A. AND LU, G. 1999. Integrating molecular genetics and ecology in speciation studies: coregonid fishes as a model system. Biol. J. Linn. Soc., 68, 173-197.

CHOUINARD, A., PIGEON, D. AND BERNATCHEZ, L. 1996. Lack of specialization in trophic morphology between genetically differentiated dwarf and normal forms of lake whitefish (Coregonus clupeaformis Mitchill) in Lac de l'Est, Québec. Can. J. Zool., 74, 1989-1998.

CLARKE, G. 1993. The genetic basis of developmental stability. I. Relationships between stability, heterozygosity and genomic coadaptation. Genetica, 89, 15-23.

GRAHAM, J. H. 1992. Genomic coadaptation and developmental stability in hybrid zones. Acta Zool. Fenn., 191, 121-131.

GRAHAM, J. H. AND FELLEY, J. D. 1985. Genomic coadaptation and developmental stability within introgressed populations of Enneacanthus gloriosus and E. obesus (Pisces, Centrarchidae). Evolution, 39, 104-114.

HATFIELD, T. 1995. Speciation in Sympatric Sticklebacks: Hybridization, Reproductive Isolation and the Maintenance of Diversity. Ph.D. Thesis, University of British Columbia.

HATFIELD, T. 1997. Fluctuating asymmetry and reproductive isolation between two sticklebacks. Envir. Biol. Fish., 49, 63-69.

LEAMY, L. 1984. Morphometric studies in inbred and hybrid house mice. V. Directional and fluctuating asymmetry. Am. Nat., 123, 579-593.

LEARY, R. F. AND ALLENDORF, F. W. 1989. Fluctuating asymmetry as an indicator of stress in conservation biology. Trends Ecol. Evol., 4, 214-217.

LEARY, R. F., ALLENDORF, F. W. AND KNUDSEN, L. K. 1984. Superior developmental stability of heterozygotes at enzyme loci in salmonid fishes. Am. Nat., 124, 540-551.

LEARY, R. F., ALLENDORF, F. W. AND KNUDSEN, L. K. 1985. Developmental instability and high meristic counts in interspecific hybrids of salmonid fishes. Evolution, 39, $1318-1326$.

LU, G. AND BERNATCHEZ, L. 1998. Experimental evidence for reduced hybrid viability between dwarf and normal ecotypes of lake whitefish (Coregonus clupeaformis Mitchill). Proc. $R$. Soc. B., 265, 1025-1030.

LU, G. AND BERNATCHEZ, L. 1999. Correlated trophic specialization and genetic divergence in sympatric lake whitefish ecotypes (Coregonus clupeaformis): support for the ecological speciation hypothesis. Evolution, 53, 1491-1505.

McPHAIL, J. D. 1984. Ecology and evolution of sympatric sticklebacks (Gasterosteus): morphological and genetic evidence for a species pair in Enos Lake, British Columbia. Can. J. Zool., 62, 1402-1408.

McPHAIL, J. D. 1993. Ecology and evolution of sticklebacks (Gasterosteus): origin of the species pairs. Can. J. Zool., 71, 515-523.

PALMER, A. R. 1994. Fluctuating asymmetry analysis: a primer. In: Markow, T. A. (ed.) Developmental Instability. Its Origins and Evolutionary Implications, pp. 335-364. Kluwer, Dordrecht.

PALMER, A. R. AND STROBECK, C. 1986. Fluctuating asymmetry: measurement, analysis, patterns. Ann. Rev. Ecol. Syst., 17, 391-421.

Pigeon, D., Chouinard, A. AND Bernatchez, L. 1997. Multiple modes of speciation involved in the parallel evolution of sympatric dwarf and normal morphotypes of lake whitefish (Coregonus clupeaformis, Salmonidae). Evolution, 51, 196-205.

REIST, J. D. 1985. An empirical evaluation of several univariate methods that adjust for size variation in morphometric data. Can. J. Zool., 63, 1429-1439.

RICE, W. R. 1989. Analyzing tables of statistical tests. Evolution, 43, 223-225.

ROBINSON, B. W. AND WILSON, D. S. 1994. Character release and displacement in fishes: a neglected literature. Am. Nat., 144, 596-627.

SCHLUTER, D. 1995. Adaptive radiation in sticklebacks: tradeoffs in feeding performance and growth. Ecology, 76, 82-90.

SCHLUTER, D. 1996. Ecological speciation in postglacial fishes. Phil. Trans. R. Soc. B., 351, 807-814.

SCHLUTER, D. 1998. Ecological causes of speciation. In: Howard, D. J. and Berlocher, S. H. (eds) Endless Forms. Species and Speciation, pp. 114-129. Oxford University Press, Oxford.

SKÚlASON, S. AND SMITH, T. B. 1995. Resource polymorphisms in vertebrates. Trends Ecol. Evol., 10, 366-370.

VAN VALEN, L. 1962. A study of fluctuating asymmetry. Evolution, 16, 125-142.

WADDINGTON, C. H. 1942. Canalization of development and the inheritance of acquired characters. Nature, 150, 563-565.

wOOD, C. C. AND FOOTE, C. J. 1990. Genetic differences in the early development and growth of sympatric sockeye salmon and kokanee (Oncorhynchus nerka), and their hybrids. Can. J. Fish. Aquat. Sci., 47, 2250-2260.

wOOD, C. C. AND FOOTE, C. J. 1996. Evidence for sympatric genetic divergence of anadromous and nonanadromous morphs of sockeye salmon (Oncorhynchus nerka). Evolution, 50, 1265-1279.

ZAKHAROV, V. M. 1989. Future prospects for population phenogenetics. Sov. Sci. Rev. F Physiol. Gen. Biol., 4, 1-79. 